\title{
Using Geographic Information System (GIS) as a Supporting Tool in Public Facilities Planning: A Case Study on the City of Nasiriyah
}

\author{
Ahmed Salman Hasan ${ }^{1}$, Khaldoon T. Falih ${ }^{2}$ \\ [ahmed.hassan@stu.edu.iq ${ }^{1}$, khaldoon@alayen.edu.iq ${ }^{2}$ ] \\ Nasiriyah Technical Institute, Southern Technical University, Iraq ${ }^{1}$ \\ Petroleum Engineering College, Al-Ayen University, Dhi-Qar, Iraq ${ }^{2}$
}

\begin{abstract}
The accessibility and development of new park facilities is an important aspect of city planning. Nasiriyah (Iraq) is a city that is in dire need of park facilities. Thus, this study aims to examine the availability of the land and select the optimum locations for public parks in the city. To achieve this, first, the existing public parks are investigated using carried out within the framework of the Analytic Hierarchy Process (AHP) by integrating with Geographic Information System (GIS). Then, a Euclidean-allocation model was used to provide a useful tool for the allocation of public facilities and to measure the accessibility for the best locations of parks. Using a decision support system software with weighting three attributes of land availability, land value, and population density. The final results identified 6 potential sites which represent only $2.1 \%$ of the total area as the most suitable land for parks.
\end{abstract}

Keywords: Geographic Information System, Park Facilities Planning, City Planning.

\section{Introduction}

Public facilities planning involves the application of planning standards. For example, how much space and area is required for planning of public parks for the welfare of people in a city. Since planning standards specified the area needed where the public facilities should be provided to the people, therefore, green spaces are an important element in bringing life into urban cities on a both social and ecological scale [1]. Green spaces reduce the rising the temperature in urban areas and make the environment very healthy and favourable [2]. Open spaces generally provide a low level of intervention and continuous functioning of the ecosystems and survival of a better environment in urban areas. The functions of open spaces are manifold but they can be categorized into two such as; the provision of recreation and the provision of better services to the people living in the society in the specified area of the city [3].

One of the important aspects of urban life is the provision of green spaces, which creates a positive contrast to the concrete structures in the city. However, there is a higher focus on other social issues such as employment, education, and safety since they have a higher effect on the general populace. As the cities begin to grow and evolve, the building of parks and green spaces in becoming an issue that can affect the city in a positive way. Thus, it is slowly becoming more important, as the city grows both financially and culturally and environmental factors start to gain more traction among the general population [4]. 
There are several studies performed in the last decade that focus on the importance of the well-being of the inhabitants of the society [5]. Most of these researches attributes the problems faced in urban environments due to an overflow of population and increasing density in urban areas. The existence of green environments in forms of parks and other forms of green elements in the city contribute towards its environmental sustainability [6].

There are also deeper ramification than simple sustainability, such as psychological relief particularly due to the COVID-19 pandemic [7]. The pandemic itself had created an environment of isolation that psychologically affected the people living in the city. The existence of parks creates the perfect starting point for people to reintegrate into society as the counties and cities open up.

One of the tools used in order to aid in the urban planning of a city, is the, the Geographic Information System (GIS) [8]. This application supports and involves all these factors in resolving the facility location problems of urban and regional planning [9]. Since planning itself contains a wide range of infrastructures such as transportation planning; infrastructure planning and public facility planning.

However, GIS can be used as an intelligent tool to find the location for public facilities and make information accessible. A facility location model used in GIS can help to minimize the travel cost and also find the closest facility location or service areas of the facility [10]. It is a viable tool used by planners in the decision-making process. This model may cover optimization solutions, which can be vital in urban planning and site planning [11]. However, it helps to find the best sites for public and private facilities in an efficient way. It is also a useful application in regional planning to predict the optimal sites for facilities within the regions by using GIS.

Furthermore, land suitability is a first phase and an effective way to decide suitable land parcels for public facilities planning. It is associated with public facility planning for example, which comprises the integration of GIS and location-allocation models [12]. GIS helps in the finding of optimal locations for public facilities and solves facilities problems, such as locating open spaces, public parks, public health facilities, and optimal location for solid waste management and the location of landfill sites [13]. It addresses the issue of the proper distribution of land use evaluation of Cities to see the public facilities of public parks, is the main single feature of the existence of urban public parks, for citizens' accessibility. It seems to be difficult for Iraq as a country to evaluate the need for public facilities using the application of GIS.

Nasiriyah is among the most populated cities in Iraq and the population is only growing. Thus, the need for sustainable public facilities is rising every year [14]. However, since Nasiriyah is located in the south of Iraq, it is prone to hot and dry weather, which can be mitigated by the inclusion of green spaces [15]. Thus, the issue of accessibility of parks as well as their abundance existence becomes even more critical in southern cities that experience above average temperature.

In this study, the issue of accessibility of parks in Nasiriyah city is addressed using land suitability analysis and facility location-allocation models through spatial analysis method of GIS. An optimal site for future public park development is based on the availability of the suitable land to be allocated, as well as other metrics that play an important role in the existence of the parks and greenspaces. 


\section{Methodology}

In this section the methodology used to conduct the research as well the location of the study are illustrated and explained. The main goal of this study is to use existing supporting tools in order to plan for the allocation of parks and green spaces in Nasiriyah. In order to do this, there first needs to be a study on Nasiriyah itself as a city and its various geographical and social aspects. Secondly, the related tools that are used to analyse the obtained data need to be examined and explained further. Finally, the methods used in order to combine the data and turning it into a readable database needs to be elaborated further.

\subsection{Study Location}

This study covers the locations of public parks for city of Nasiriyah. This city is considered to be among the top most important states and settlements in Iraq. It is centrally located on $32^{\circ}$ $30^{\prime}$-north latitudes and $47^{\circ} 12^{\prime}$-east longitudes. Nasiriyah experienced an increase in population growth of about $3.0 \%$ to $3.5 \%$ from the years 1937 to 2017 . Assuming the same growth rate, the population of Nasiriyah will increase from 285,707 in 1937 to 219,3253 in 2017 and 235,8075 in 2020 Nasiriyah [16]. The location map of Nasiriyah city is shown in Figure 1.

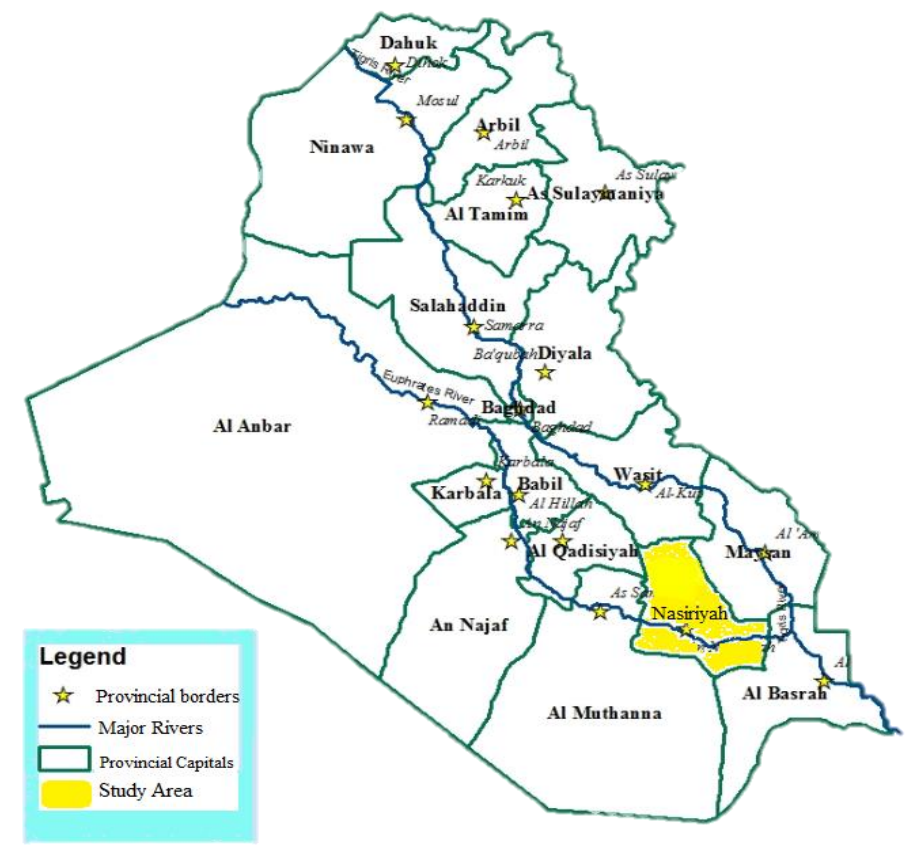

Fig. 1. Map of Iraq highlighting the location of Nasiriyah 


\subsection{Data Source}

The data sources for this study are based on several sources such as official government documents, published reports, books and journals, literature studies and architectural sources. The base map was obtained the city planning department in form of a spatial map. The land value was obtained via a market survey. The report published by the city under the title of "The development plan of Nasiriyah $(2000-2020)$ " provided both the population density as well as the income level [16]. Everything else included in this research was obtained via official sources.

\subsection{Methods}

The land Suitability Analysis and Analytic Hierarchy Process (AHP) manages the several criteria/factors of a problem into a hierarchy related to a tree form arrangement, it is mandatory to build up a Hierarchical Structure Model (HSM) for Land Suitability Analysis (LSA) based on experts discussions to define the goal, criteria, and parameters to solve and set the problem [17]. The HSM is the major component of this study. It is divided into three main levels; goal, criteria, and sub-criteria. The goal level is the uppermost level, which defines the problem. The second level is the level of criteria comprising three aspects. The third level consists of various sub-criteria. This hierarchical model is illustrated in Figure 2.

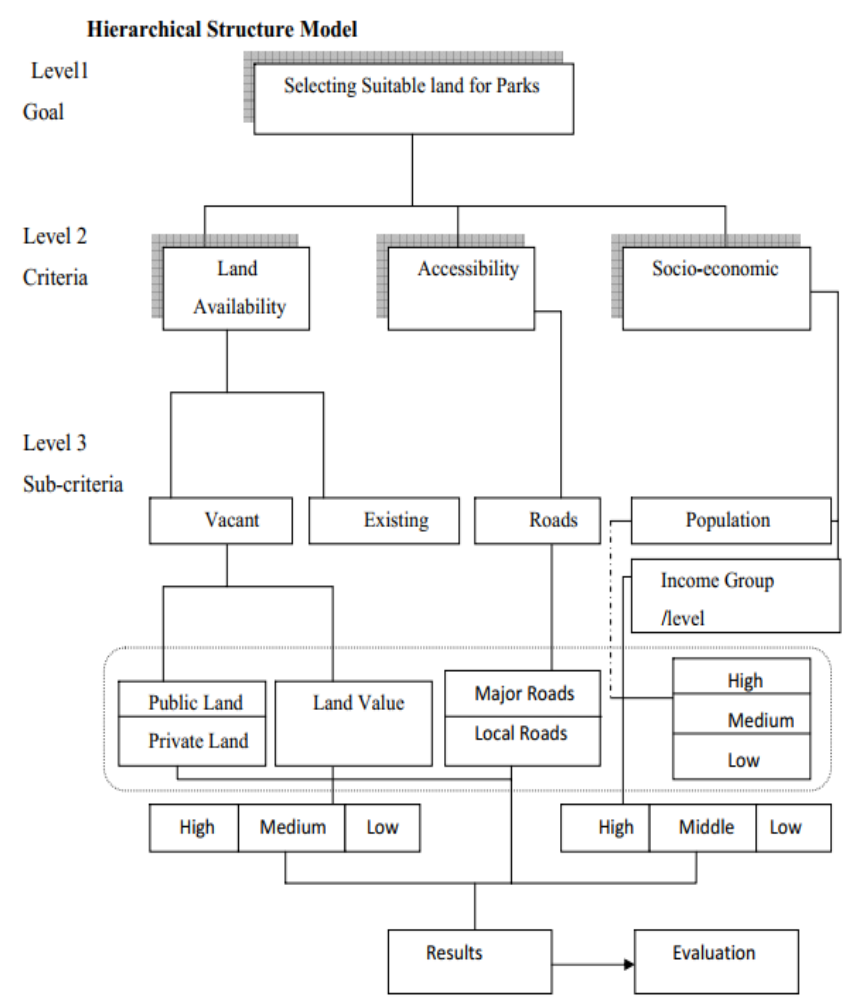

Fig. 2. Hierarchical Structure Model of selecting suitable Land for Parks 


\subsection{Database Development}

Using the HST illustrated in Figure 2, the GIS database is developed using the level 2 and level 3 criteria. ArcGIS 9.2 is used in order to convert the scanned map of Nasiriyah into digitized data layers based on the mapped out earth coordinates previously geo referenced. The development purpose of the database was to generate data layers for this project including landuse (polygons) and roads (Line). The other data layers created land value, population density, and income group level. In addition, data layers were applied to evaluate existing parks, land suitability analysis to find out suitable land for public parks planning and to determine optimal locations for public parks planning [18].

A Multiple Criteria Decision Making (MCDM) is used in order to interlink the criteria via the system. MCDM operates by using a set of alternatives that are evaluated based on differing and incommensurate criteria. With the use of an Expert Choice (EC) software, the composite weights are calculated using a pairwise comparison system. Using this form of sorting helps in identifying the perfect priorities in relation to the attributes and their relative weight to one another. Once the composite weights is calculate or each of the parameters, a suitability analysis is performed using the special analysis function of GIS. This function helps to produce composite scenario maps for park development.

A suitability analysis is performed in order to create three scenarios by using spatial analysis in geographic information system (GIS). Each of these scenarios correspond to the attributes calculated using the expert system based on the hierarchical structure model in Figure 2. In this case, the three chosen scenarios are based on land availability, land value and population density. These attributes have shown to narrow down the suitability analysis in a more accurate method based on each scenario.

The results of the multiplication of weights were added to get the total. Factors and parameters were determined based on scenarios, for land suitability. The results of composite weights were used in GIS spatial analysis to generate scenario maps finding suitable land for park development.

\subsection{Data Reclassification and Projection}

The reclassification of values from old values to new values was accomplished with the support of spatial analyst ArcGIS 9.2. Then the raster dataset is transformed from one projection to another. The obtained land suitability scenario maps were projected after using the Weighted Sum function [19]. The coordinate system enabled the map to be represented in two dimensions, as $\mathrm{x}, \mathrm{y}$ coordinates. Then the function of times is to multiply the values of two rasters on a cellby-cell basis. This function is applied to produce the suitability map [20]. The results of suitability analysis are several suitability maps that represent areas from most suitable to least suitable. The final map of suitability was created into non-developable (excluded) and most suitable (or developable). Scenarios were assessed by using number of grid cells for the degree of land suitability analysis such as most suitable, moderately suitable, and least suitable. Euclidean allocation model was applied to determine the accessibility by using GIS spatial analysis for suitable land of parks. 


\section{Results}

Suitability analysis was done through the combination of GIS and AHP methods. All three scenarios are calculated using the AHP method. To produce all three scenarios in ArcGIS (9.2), a land-use map was converted into raster format by using Spatial Analyst to classify sub-criteria (parameters). Several steps were taken in order to create land availability scenario. First, the sub-criteria (parameters) were reclassified in order to produce excluding maps. Then, all classified maps were added on a composite weight (Wi). All the maps were projected, and summed together. Finally, the summed up maps were projected to get the land availability scenario. Figure 3 illustrates the maps for each of the three scenarios.

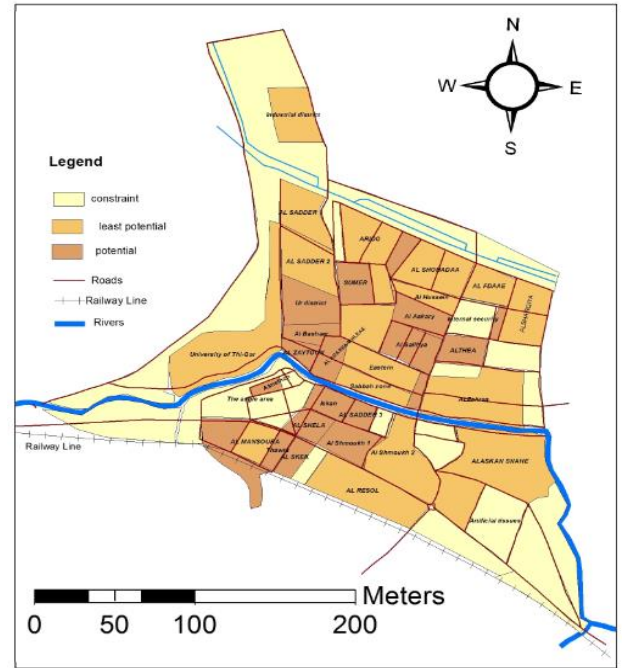

(a)

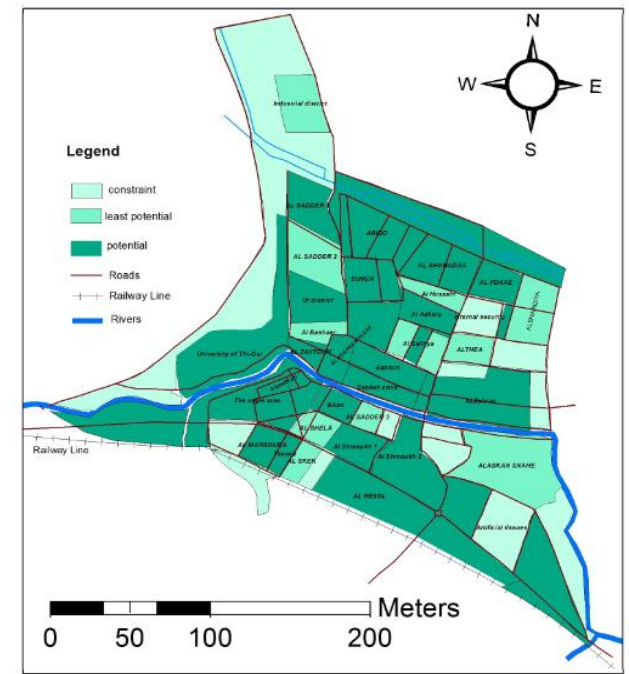

(b)

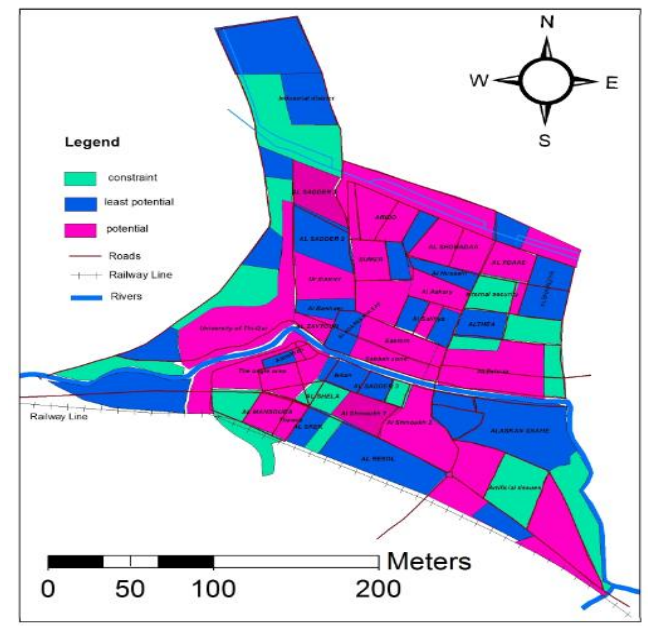

(c)

Fig. 3. Maps for (a) scenario 1 - Land Availability, (b) scenario 2 - Land Value, (c) scenario 3 Population Density 
The maps illustrated are a total of 510,880 grid cells in total for Nasiriyah. Performing the AHP and GIS methods for public parks suitability analysis resulted in three categories of potential, least potential and constraint land. For the first scenario based on land availability resulted in only $15 \%$ of the land being marked as potential $(73,400$ grid cells), while $60 \%$ and $25 \%$ are least potential and constraint land respectively with 288,240 and 149,240 grid cells. For the second scenario, the focus is land value in which roughly $63 \%$ is considered potential land (296,120 grid cells), while the remaining $14 \%$ and $23 \%$ are least potential and constraint land respectively. For the final and third scenario, the focus is on population density and the potential land is considered $69 \%$, which translates to 326,080 grid cells. The remaining $25 \%$ and $6 \%$ are leas potential and constraint land.

\section{Discussion}

The results indicate that from 510880 total grids, an estimated 316080 grids ( $66 \%$ or 790.2 hectares) are potential land, 84120 grids (15\% or 210.3 hectares) are the least potential land and 110600 grids (19\% or 276.5 hectares) are a constraint for parks development. All scenarios reclassified in model builder as added through Weighted Sum to produce potential land. While the potential land map was projected to get the correct suitability map for park locations in Nasiriyah city. Figure 4 illustrates the suitability map for park allocation in Nasiriyah with potential spots marked in red, less potential marked with dark green and constraint areas marked with bright green.

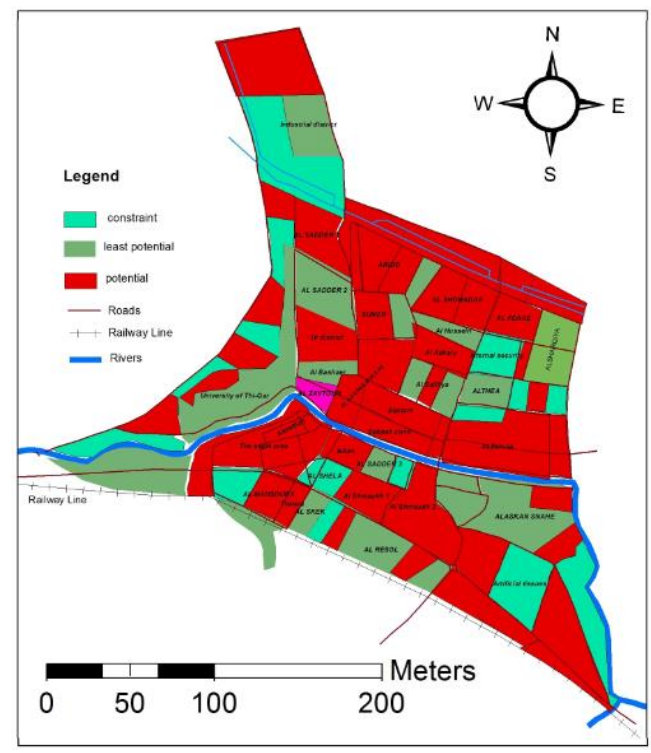

Fig. 4. Suitability map for park allocation in Nasiriyah 


\section{Conclusion}

The main objective of this study was to determine the best location for parks in Nasiriyah city (Iraq). In order to accomplish this, an Analytic Hierarchical Process (AHP) based on GIS integrated approach was used. This research provided a framework based on MCDA that was applied on park planning in a GIS spatial map network. Using this context, a hierarchical structure model was used for selecting the suitable land based on a set of criteria and sub criteria. Using the parameters, the problem of locating facility planning for parks ultimately lead to identification of several potential park locations with a degree of success.

Using the GIS combined with AHP, the results indicated that based on each parameter and scenario, the land availability was identified to be as follows. For the first scenario, of land availability, the potential land for parks was identified to be at only $10 \%$, and the second scenario of land value the availability was set at $64 \%$. Finally, for the third scenario, the population density, the potential land was identified to be at $69 \%$. This data is then combined into a single map that can mark the most potential locations for maps.

This research can be further improved by the use of more accurate data. This is mainly because the data was not readily available from the various governmental institutes. The more data applied to the decision making system, the more accurate the results will be. Ultimately, this research is very useful for further studies that plan a similar objective on a different location. Other researchers can use the framework provided in this research in order to identify the suitability of parks in different location and cities.

\section{References}

[1] Wolf, K.: 'The health benefits of small parks and green spaces', Parks \& Recreation. 52 (4): 28-29., 2017, 52, (4), pp. 28-29

[2] Barbosa, O., Tratalos, J.A., Armsworth, P.R., Davies, R.G., Fuller, R.A., Johnson, P., and Gaston, K.J.: 'Who benefits from access to green space? A case study from Sheffield, UK', Landscape and Urban planning, 2007, 83, (2-3), pp. 187-195

[3] Maruani, T., and Amit-Cohen, I.: 'Open space planning models: A review of approaches and methods', Landscape and urban planning, 2007, 81, (1-2), pp. 1-13

[4] Van Herzele, A., and Wiedemann, T.: 'A monitoring tool for the provision of accessible and attractive urban green spaces', Landscape and urban planning, 2003, 63, (2), pp. 109-126

[5] Bahriny, F., and Bell, S.: 'Patterns of urban park use and their relationship to factors of quality: a case study of Tehran, Iran', Sustainability, 2020, 12, (4), pp. 1560

[6] Li, Z., Wei, H., Wu, Y., Su, S., Wang, W., and Qu, C.: 'Impact of community deprivation on urban park access over time: Understanding the relative role of contributors for urban planning', Habitat International, 2019, 92, pp. 102031

[7] Geng, D.C., Innes, J., Wu, W., and Wang, G.: 'Impacts of COVID-19 pandemic on urban park visitation: a global analysis', Journal of forestry research, 2021, 32, (2), pp. 553-567

[8] Ergen, M.: 'Using geographical information systems to measure accessibility of green areas in the urban center of Nevşehir, Turkey', Urban Forestry \& Urban Greening, 2021, 62, pp. 127160

[9] Church, R.L.: 'Geographical information systems and location science', Computers \& Operations Research, 2002, 29, (6), pp. 541-562

[10] Miller, H.J., and Shaw, S.-L.: 'Geographic information systems for transportation: principles and applications' (Oxford University Press on Demand, 2001. 2001) 
[11] Zhou, J., Wu, Y., Wu, C., He, F., Zhang, B., and Liu, F.: ‘A geographical information system based multi-criteria decision-making approach for location analysis and evaluation of urban photovoltaic charging station: A case study in Beijing', Energy Conversion and Management, 2020, 205, pp. 112340

[12] Rahman, M., Chen, N., Islam, M.M., Dewan, A., Pourghasemi, H.R., Washakh, R.M.A., Nepal, N., Tian, S., Faiz, H., and Alam, M.: 'Location-allocation modeling for emergency evacuation planning with GIS and remote sensing: A case study of Northeast Bangladesh', Geoscience Frontiers, 2021, 12, (3), pp. 101095

[13] Chiesura, A.: 'The role of urban parks for the sustainable city', Landscape and urban planning, 2004, 68, (1), pp. 129-138

[14] Satchet, M.M.S., and Aodah, M.H.H.: 'Transit GIS Applications For parking in Nasiriyah City, Iraq', Journal of university of Thi-Qar scientific Vol, 2010, 5, (1), pp. 12

[15] Vieira, J., Matos, P., Mexia, T., Silva, P., Lopes, N., Freitas, C., Correia, O., Santos-Reis, M., Branquinho, C., and Pinho, P.: 'Green spaces are not all the same for the provision of air purification and climate regulation services: The case of urban parks', Environmental Research, 2018, 160, pp. 306-313

[16] Falih, K.T.: 'Spatial Analysis of Educational Services Using GIS in Nasiriyah City', Turkish Journal of Computer and Mathematics Education (TURCOMAT), 2021, 12, (5), pp. 1974-1984

[17] Yariyan, P., Zabihi, H., Wolf, I.D., Karami, M., and Amiriyan, S.: 'Earthquake risk assessment using an integrated Fuzzy Analytic Hierarchy Process with Artificial Neural Networks based on GIS: A case study of Sanandaj in Iran', International Journal of Disaster Risk Reduction, 2020, 50, pp. 101705

[18] Stewart Fotheringham, A., and Rogerson, P.A.: 'GIS and spatial analytical problems', International Journal of Geographical Information Science, 1993, 7, (1), pp. 3-19

[19] Wong, N.H., and Jusuf, S.K.: 'GIS-based greenery evaluation on campus master plan', Landscape and urban planning, 2008, 84, (2), pp. 166-182

[20] Mendoza, G.A.: 'GIS-based multicriteria approaches to land use suitability assessment and allocation', United States Department Of Agriculture Forest Service General Technical Report NC, 2000, pp. 89-94 